\title{
PROCESSING OF EXPERIMENTAL DATA OF THE PROCESS OF REFINING NUCLEAR MATERIAL Zr1\%Nb BY ELECTRON-BEAM MELTING BY MEANS OF INTERVAL ANALYSIS METHODS
}

\author{
A.V. Yefimov' ${ }^{1}$,M.M. Pylypenko ${ }^{2}$, T.V. Potanina ${ }^{1}$, T.A. Yesypenko ${ }^{1}$, \\ T.A. Harkusha ${ }^{1}$, Yu.S. Stadnik ${ }^{2}$ \\ ${ }^{I}$ National Technical University "Kharkiv Polytechnic Institute”, Kharkiv, Ukraine \\ E-mail: AVEfimov@kpi.kharkov.ua; \\ ${ }^{2}$ National Scientific Center "Kharkov Institute of Physics and Technology”, Kharkiv, Ukraine \\ E-mail:mpylypenko@kipt.kharkov.ua
}

The possibilities of applying the methods and models of interval analysis, which take into account the uncertainties in the specification of data for $\mathrm{Zr} 1 \% \mathrm{Nb}$ alloys, to more accurately determine the relationship between the microhardness of $\mathrm{Zr} 1 \% \mathrm{Nb}$ alloy samples and the content of oxygen in them, have been investigated. The correctness of the application of methods and models of interval analysis for processing the results of experiments to study the properties of nuclear materials is shown.

\section{INTRODUCTION}

Further improvement of nuclear and radiation safety and efficiency of nuclear power plants requires highquality structural materials, which provide an increase in the duration of the campaigns of nuclear reactors and increase the efficiency of their operation. This, in turn, leads to an increase in requirements for the properties of materials, their purity, size and number of defects in structural elements.

The main structural material of the reactor cores on thermal neutrons with a water heating agent are zirconium alloys with a low capture cross section for thermal neutrons, good radiation and corrosion resistance.

It is known that even very small additives of impurities influence effectively the physic mechanical and physic chemical properties of zirconium and alloys based on it, which may entail a change in the mechanical and corrosion properties of zirconium alloys, as well as a change in the optimal deformation and heat treatment conditions [1]. In addition, the influence of the total content of the composition of impurities on the properties of zirconium alloys is also possible.

In zirconium alloys for nuclear reactors, the content of about 20 impurities is normalized. The effect of impurities on the properties of zirconium alloys is diverse. It is known that hafnium increases the coefficient of capture of thermal neutrons; aluminum and titanium reduce the corrosion resistance of zirconium in water at high temperatures; iron, silicon and chlorine reduce the fracture toughness and thereby impair processability and crack resistance of products; increased oxygen content to 0.14 wt. $\%$ in the alloy impairs the technological properties of this alloy in the manufacture of pipes, and also leads to a decrease in the performance characteristics of the pipes produced [2]. To meet the growing requirements for zirconium products for nuclear reactors, it is necessary to reduce the concentrations of impurities that adversely affect them to the minimum values. Therefore, obtaining a zirconium alloy with a low content of these impurities, especially oxygen, is one of the conditions for its use in the nuclear industry.

On the basis of studies of the behavior of individual impurities or their groups in the refining of metals by various physical methods, it was found that electron beam melting (EBM) in high vacuum is one of the most effective methods for refining zirconium and makes it possible to produce zirconium, from which it is possible to manufacture alloys and products for nuclear technology.

Analysis of the generalized results of the systematic studies of zirconium refining process shows that the use of the EBM method can significantly reduce the concentrations of metal and gas impurities, while the microhardness of zirconium also decreases from 1200 to $800 \mathrm{MPa}$ [3, 4]. Impurities of implantation (oxygen, nitrogen, carbon) and metal impurities significantly affect the mechanical and corrosion properties of zirconium, so much attention is paid to the issues of obtaining high-purity zirconium with a low content of these impurities by the EBM method.

One of the ways to obtain high-quality ingots of zirconium alloy with $1 \%$ niobium $(\mathrm{Zr} 1 \% \mathrm{Nb})$ is to conduct EBM under optimal process conditions. The optimal technological regimes and parameters (specific power, vacuum conditions, etc.) are those at which the required indicator of cleaning of the $\mathrm{Zr} 1 \% \mathrm{Nb}$ alloy ingots from impurities is achieved in accordance with the standards.

Thus, the values of microhardness of the alloy samples after melting show the efficiency of the EBM method in terms of providing the necessary existing standards for the chemical composition of the $\mathrm{Zr} 1 \% \mathrm{Nb}$ alloy ingots. It is believed that the dependence of microhardness on the content of impurities has a close to linear character [5].

At the same time, it should be noted that the existing standards allow differences in the chemical composition of the $\mathrm{Zr} 1 \% \mathrm{Nb}$ alloy ingots (also, by the way, in ingots of other alloys of nuclear materials) within the limits of technical requirements. In particular, according to TU 95.166-98, the amount of niobium in the $\mathrm{Zr} 1 \% \mathrm{Nb}$ alloy is normalized from 0.9 to $1.1 \mathrm{wt} \%$, and the 
content of some impurities is limited only by maximum values. In other words, there are uncertainties in the data themselves, which assess the quality of the alloy ingot. And this affects the accuracy of determining the dependences of microhardness on the content of impurities, and, in particular, oxygen.

It should be noted that such uncertainty is inherent in any process of research and evaluation of experimental data. It contains measurement errors, noise, rounding errors, incompleteness of information, uncertainty caused by methodological errors. It is impossible to overcome the conditions of all these uncertainties, but the analysis of numerous scientific papers on the processing of experimental data shows that one can consider an interval model as one of the most correct models for processing these data [6-10].

Taking this into account, it seems relevant to study the possibility of using mathematical methods and interval analysis models, which allow to take into account the uncertainties of the data, which assess the quality of ingots of nuclear material alloys after EBM, to determine the oxygen content in $\mathrm{Zr} 1 \% \mathrm{Nb}$ alloy depending on the hardness of the alloy.

\section{INITIAL DATA AND TASK SETTING}

The results of the experimental study of the relationship between the microhardness of a $\mathrm{Zr} 1 \% \mathrm{Nb}$ alloy sample and the content of oxygen in it are presented in Fig. 1 [4]. It shows the experimental data in the form of variations of nine microhardness values of samples represented by intervals (taking into account the standard instrument error of measurements of 5\%) and the corresponding values of oxygen content. The dots in the figure show the average values of the sample hardness in each of the intervals. The curve of hardness versus percentage of oxygen in Fig. 1 is the approximation of experimental data using the least squares method (LSM) [11]. The boundaries of the measurement intervals, the values of the "average" microhardness at each value of the percentage of oxygen, as well as the uncertainty intervals of observations of the hardness values, taking into account the measurement error, are presented in Table.

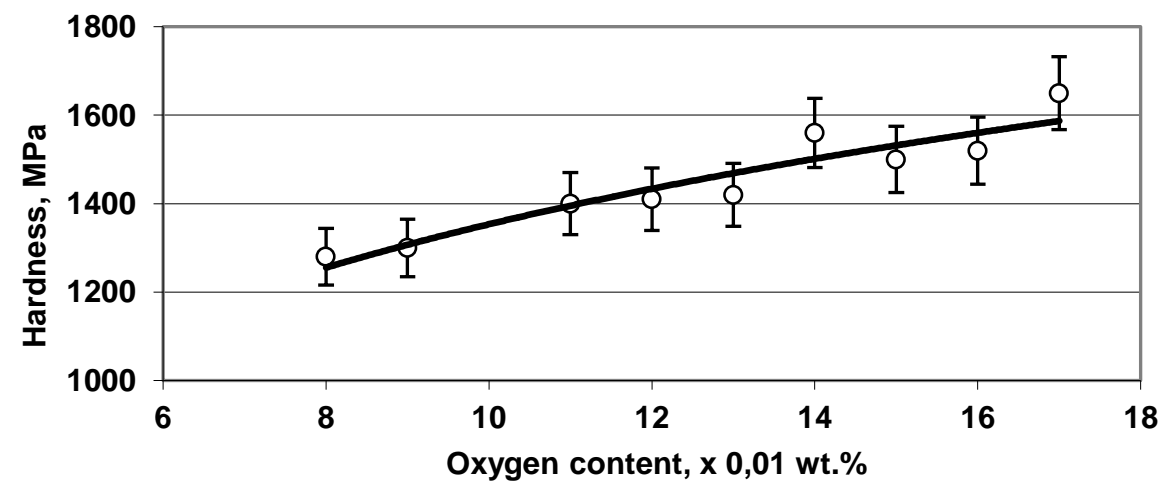

Fig. 1. The results of the experimental study of the relationship between the microhardness of Zr1\%Nb alloy samples and the content of oxygen in it

Experimental data for $\mathrm{Zr} 1 \% \mathrm{Nb}$ alloy

\begin{tabular}{|c|c|c|c|c|c|}
\hline \multirow{2}{*}{$\begin{array}{c}\text { Oxygen content, } \\
\text { wt. } \%\end{array}$} & \multicolumn{3}{|c|}{ Microhardness, $\mathrm{MPa}$} & \multirow{2}{*}{$\begin{array}{l}\text { Average spread of } \\
\text { microhardness } \\
\text { values, } \%\end{array}$} & \multirow{2}{*}{$\begin{array}{c}\text { Uncertainty intervals of } \\
\text { observation of } \\
\text { microhardness values }\end{array}$} \\
\hline & $\min$ & average & $\max$ & & \\
\hline 0.08 & 1260 & 1280 & 1300 & 1.56 & {$[1216 ; 1344]$} \\
\hline 0.09 & 1280 & 1300 & 1320 & 1.54 & {$[1235 ; 1365]$} \\
\hline 0.11 & 1379 & 1400 & 1421 & 1.50 & {$[1330 ; 1470]$} \\
\hline 0.12 & 1388 & 1410 & 1431 & 1.49 & {$[1340 ; 1481]$} \\
\hline 0.13 & 1399 & 1420 & 1441 & 1.48 & {$[1349 ; 1491]$} \\
\hline 0.14 & 1537 & 1560 & 1597 & 2.37 & {$[1482 ; 1638]$} \\
\hline 0.15 & 1477 & 1500 & 1523 & 1.53 & {$[1425 ; 1575]$} \\
\hline 0.16 & 1497 & 1520 & 1543 & 1.51 & {$[1444 ; 1596]$} \\
\hline 0.17 & 1625 & 1650 & 1675 & 1.52 & {$[1568 ; 1733]$} \\
\hline
\end{tabular}

Unknown probabilistic characteristics of the sample data (see in Table) as well as the theoretically possible presence of errors or outliers in them, make it impossible to strictly justify the application of standard statistical procedures for processing these experimental data. This is due to the fact that the application of standard statistical data processing procedures is correct under the condition of representativeness of the sample (the length must be large enough), the normality of the distribution of measurement errors (the error must be probabilistic and its distribution must be normal and undisplaced), the values of the main argument must be accurate.

Interval analysis methods and models can serve as an effective means for overcoming the collisions arising in this way [7-9].

Let us consider in more detail the rationale and procedure for their use for statistical processing of the 
results of an experiment to determine the relationship between the microhardness of the $\mathrm{Zr} 1 \% \mathrm{Nb}$ alloy sample and the content of oxygen in it.

It is known that for a wide range of tasks of constructing a mathematical model based on the results of an experiment, the dependence being formalized is the following:

$$
y=\varphi(\mathbf{x}, \mathbf{b})+\varepsilon_{y}
$$

where $\mathbf{x}=\left(x_{1}, \ldots, x_{n}\right) \in X$ is the vector of input variables; $\mathbf{b}$ - the vector of model parameters; $y$ - the output variable; $\varphi-$ the function describing the deterministic component of the dependence of $y$ on $x$, and $\varepsilon_{y}$ - the value describing the uncertainty of the presented dependence.

In the probabilistic model which is the most common among other methods of constructing a model of the dependence between the input and output variables - component $\varepsilon_{y}$ is a normally distributed random variable, with a mean of zero and standard deviation $\sigma_{y}$. The uncertainty of the variable $y$ for a given confidence level is described by a confidence interval (the so-called rule " $2-\sigma$ "):

$$
y-2 \sigma_{y} \leq y \leq y+2 \sigma_{y},
$$

where $y$ is the point estimate of the unknown quantity obtained as a result of the experiment.

The interval model [6, 7] does not impose requirements for the subordination of the absolute error $\varepsilon_{y}$ to any distribution law, but only considers its limitations: $\left|\varepsilon_{y}\right| \leq \varepsilon$. What, in fact, is accepted in metrology is the assumption that the value $y$ is obtained using an inaccurate instrument with a known error $\varepsilon_{y}$. And then for any value of $y$ there is an interval of uncertainty:

$$
[y]=\left[y-\varepsilon_{y} ; y+\varepsilon_{y}\right]
$$

moreover, the interval can always be extended when new sources of errors are detected and their quantitative evaluation is possible.

In such conditions, the use of interval analysis methods can provide more complete information about the process under study.

\section{RESULTS AND THEIR DISCUSSION}

As the estimated structure of the constructed relationship between the variable $x$ - the percentage of oxygen in the $\mathrm{Zr} 1 \% \mathrm{Nb}$ alloy sample and the output variable $y$ - the microhardness of the sample based on studies [10] and others, let us take the linear relationship:

$$
y=b_{1}+b_{2} x+\varepsilon,
$$

where $b_{1}, b_{2}$ - parameters.

The following values are estimated from (4): the set of real values of parameters $B=\left\{b_{1}, b_{2}\right\}$ - in terms of interval analysis "information set" [9] or the set of uncertainty [6] (the international name of the membership set is the set of joint values), and the range of actual values of the dependence (4).

The experiment data is represented by the sample:

$$
\left\{y_{i}, x_{i}, i=1, \ldots, N\right\} \text {, }
$$

$y_{i}$ - observation of dependence; $x_{i}$ - argument value; $N=9$ - sample length. We assume that the values are known exactly.

The results of observations $y_{i}$ have the same accuracy with the maximum relative error $\Delta_{\max }=5 \%$, absolute $-\varepsilon_{\max }=\left|y_{i}\right| \Delta_{\max }$. At the same time, it should be noted that, in the general case, the maximum error values $y_{i}$ may be different for different observations.

Direct consideration of the error limit in constructing the interval of uncertainty of the $i$-th measurement $H_{i}$ for each measurement value from the sample (5) in the case of equal observations is carried out according to the rule:

$$
H_{i}=\left[y_{i}-\varepsilon_{\max } ; y_{i}+\varepsilon_{\max }\right] .
$$

Each uncertainty interval $H_{i}, i, \ldots, N$, contains possible values of the measured value, consistent with this measurement, that is, at least one curve of dependence (4) can be drawn through all intervals of uncertainty.

From (4) and (6) follow the constraints for the set of uncertainties (information set, the membership set):

$$
\begin{aligned}
& y_{i}-\varepsilon_{\max } \leq b_{1}+b_{2} x_{i} \leq y_{i}+\varepsilon_{\max }, \\
& \quad i=1, \ldots, N
\end{aligned}
$$

In [10], the concept of the "uncertainty center method" was introduced to determine the point and interval estimates of the set of parameters of the dependency model. This method is characterized by the fact that the type of the modeled dependence is not necessarily related to linear parametric functions, the external estimate of the set of uncertainties $B$ is a hyperparallelepiped with faces that are parallel to the coordinate planes, and its sides $\left[b_{j} ; \overline{b_{j}}\right]$ are determined from the following:

$$
\underline{b_{j}}=\min _{\mathbf{b} \in B} b_{j}, \overline{b_{j}}=\max _{\mathbf{b} \in B} b_{j},
$$

and the intervals $\left[b_{j} ; \overline{b_{j}}\right]$ contain all possible point estimates for the parameters $b_{j}, j=1, \ldots, n+1$ of dependence (1), and the lengths of intervals can be considered as measures of point estimates. The construction of a point estimate $\mathbf{b}=\left(\hat{b}_{1}, \ldots, \hat{b}_{n+1}\right)-$ the midpoint of the hyper-parallelepiped - is carried out according to the formula:

$$
\hat{b}_{i}=\frac{\overline{b_{i}}+\underline{b_{i}}}{2}, \Delta b_{i}=\frac{\overline{b_{i}}-\underline{b_{i}}}{2}, i=1, \ldots, n+1 .
$$

Problem (8) with constraints (7) relates to linear programming problems. The solution of this problem will be interval estimates of parameters (4): 


$$
\hat{b}_{1} \in\left[\underline{b_{1}} ; \overline{b_{1}}\right], \hat{b}_{2} \in\left[\underline{b_{2}} ; \overline{b_{2}}\right] .
$$

The point estimate of the parameters of dependence (4) by the method of uncertainty center can be quite close to the estimate made using the method of least squares. This is the consequence of the rather simple structure of the set of uncertainties. In the case of two parameters of the set of uncertainties, $B$ is a polygon on the plane. But, generally speaking, a point estimate based on statistical methods often determines a point that does not belong to the multitude of uncertainties.

The multitude of uncertainties of the observations (6) are the data of the considered experiment to determine the relationship between the microhardness of the $\mathrm{Zr} 1 \% \mathrm{Nb}$ alloy sample and the percentage of oxygen in it in accordance with the data in Table. Namely:

$$
\begin{aligned}
& H_{1}=[1216 ; 1344], H_{2}=[1235 ; 1365], \\
& H_{3}=[1330 ; 1470], H_{4}=[1340 ; 1481], \\
& H_{5}=[1349 ; 1491], H_{6}=[1482 ; 1638], \\
& H_{7}=[1425 ; 1575], H_{8}=[1444 ; 1596], \\
& H_{9}=[1568 ; 1733] .
\end{aligned}
$$

Accordingly, conditions (7) take the form:

$$
\begin{aligned}
& 1216 \leq b_{1}+0.08 b_{2} \leq 1344, \\
& 1235 \leq b_{1}+0.09 b_{2} \leq 1365, \\
& 1330 \leq b_{1}+0.11 b_{2} \leq 1470, \\
& 1340 \leq b_{1}+0.12 b_{2} \leq 1481, \\
& 1349 \leq b_{1}+0.13 b_{2} \leq 1491, \\
& 1482 \leq b_{1}+0.14 b_{2} \leq 1638, \\
& 1425 \leq b_{1}+0.15 b_{2} \leq 1575, \\
& 1444 \leq b_{1}+0.16 b_{2} \leq 1596, \\
& 1568 \leq b_{1}+0.17 b_{2} \leq 1733, \\
& b_{2} \geq 0 .
\end{aligned}
$$

The sign of the parameter $b_{2}$ was chosen from the considerations that the dependence of microhardness of the zirconium alloy samples on the percentage of oxygen has the form of an increasing function (see Fig. 1).

The information set $B$, which is the solution of the system (12), is presented in Fig. 2. It determines the possible values of the parameters $b_{1}$ and $b_{2}$ in dependencies (4). This set is a pentagon with vertices:

$$
\begin{aligned}
& \mathbf{b}^{1}=\left(b_{2} ; b_{1}\right)=(2538 ; 1137), \\
& \mathbf{b}^{2}=(3300 ; 1068), \\
& \mathbf{b}^{3}=(4750 ; 836), \\
& \mathbf{b}^{4}=(4433 ; 861), \\
& \mathbf{b}^{5}=(2867 ; 1081) .
\end{aligned}
$$

Extreme corner points defining the size of the set B are the points $\mathbf{b}^{3}=(4750 ; 836) \quad$ and $\mathbf{b}^{1}=(2538 ; 1137)$. Thus, the approximation of the set $B$ will be a rectangle $\Pi^{+}=\left\{\left(b_{2}, b_{1}\right): 2538 \leq b_{2} \leq 4750 ; 836 \leq b_{1} \leq 1137\right\}$.
It is obvious that $B \subset \Pi^{+}$, that is, the rectangle contains those values of the parameters $b_{1}$ and $b_{2}$ that do not satisfy conditions (12). Moreover, the difference of $\Pi^{+}$from $B$ is rather significant, since the polygon $B$ has a strongly elongated shape.

The point estimate of the dependence (4) parameters by the method of uncertainty center [10] gives the result:

$$
\begin{aligned}
& \hat{b}_{1}=\frac{\overline{b_{1}}+\underline{b}_{1}}{2}=\frac{1137+836}{2}=986.5 ; \\
& \hat{b}_{2}=\frac{\overline{b_{2}}+\underline{b_{2}}}{2}=\frac{2538+4750}{2}=3644 .
\end{aligned}
$$

The center of gravity of the set $B$ can also be taken as a point estimate [6]:

$$
\mathbf{b}=\frac{1}{k} \sum_{i=1}^{k} \mathbf{b}^{i},
$$

where the summation is carried out over all corner points of the information set $B(13)$ :

$b_{1}=\frac{1}{5} \sum_{i=1}^{5}, b_{1}^{i}=997, b_{2}=\frac{1}{5} \sum_{i=1}^{5}, b_{2}^{i}=3578$.

In the problem under consideration, the point estimates (16) and (17) of the parameters are fairly close.

LSM-estimation of parameters, found by the standard least square's method:

$$
b_{1}=1015, b_{2}=3143 \text {. }
$$

Note that this point lies outside the resulting information set, that is, it is inconsistent with the sample. The possibility of such a situation has already been discussed above.

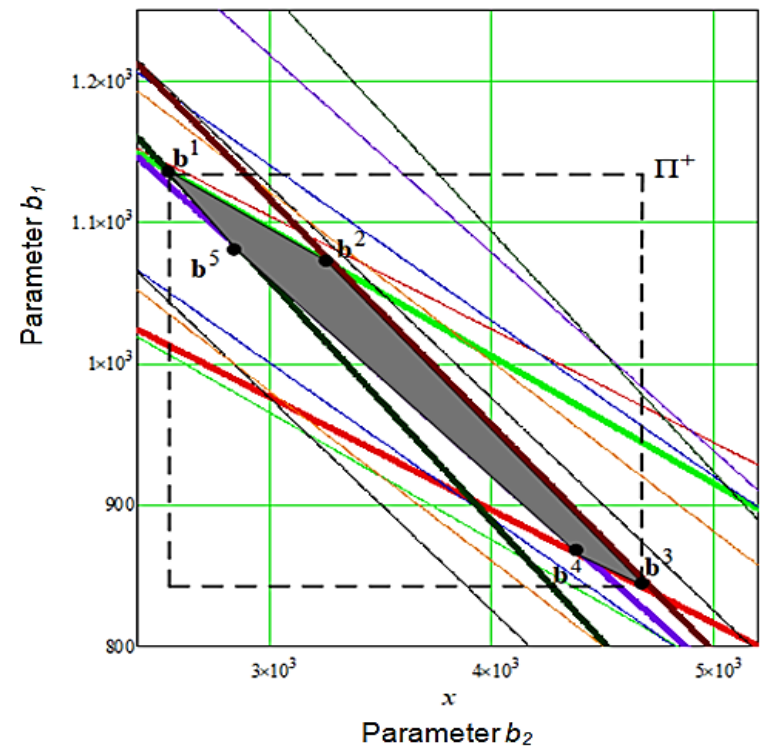

Fig. 2. Information set $B$

The second important task of interval data processing of the experiment to determine the relationship between the microhardness of the $\mathrm{Zr} 1 \% \mathrm{Nb}$ alloy sample and the percentage of oxygen in it is to estimate the values of dependence (4) in order to use the constructed model to predict the interdependence between the mentioned parameters. 
Interval estimation of the output variable $y$ of dependence (4) at the point $x$ :

$$
\underline{y(\mathbf{x})}=\min _{\mathbf{b} \in B} \mathbf{b x}, \overline{y(\mathbf{x})}=\max _{\mathbf{b} \in B} \mathbf{b} \mathbf{x} .
$$

The relation (19) shows that the set of admissible values of dependence (4) is built on the basis of the constructed set of parameter $B$ uncertainty (the membership set).

The "tube" $[\underline{y(\mathbf{x})} ; \overline{y(\mathbf{x})}]$ contains possible values of $\mathrm{y}$ at a point $\mathrm{x}$ with a different choice of dependency parameters.
The results of this estimation are presented in Fig. 3. The broken lines 1 show the conditional initial dependence tube constructed from the experimental data (11); solid lines 2 define the boundaries of the tube of real values [9], constructed from the relations:

$$
\begin{gathered}
\bar{F}\left(x_{i}\right)=\min _{\mathbf{b}^{j}}\left(b_{1}^{j}+b_{2}^{j} x_{i}\right), j=1, \ldots, 5 ; i=1, \ldots, N, \\
\underline{F}\left(x_{i}\right)=\max _{\mathbf{b}^{j}}\left(b_{1}^{j}+b_{2}^{j} x_{i}\right), j=1, \ldots, 5 ; i=1, \ldots, N,
\end{gathered}
$$

where $\mathbf{b}^{j}, j=1, \ldots, 5$ - vertices of the set $B$, namely

$$
\begin{aligned}
& \left\{x_{i}\right\}=\{0.08,0.09,0.11,0.12,0.14,0.15,0.16,0.17\}, \\
& \left\{\bar{F}\left(x_{i}\right)\right\}=\{1340,1365,1431,1464,1530,1563,1596,1643\}, \\
& \left\{\underline{F}\left(x_{i}\right)\right\}=\{1216,1260,1349,1393,1482,1511,1540,1568\} .
\end{aligned}
$$

Tube section width:

$$
\left\{\bar{F}\left(x_{i}\right)-\underline{F}\left(x_{i}\right)\right\}=\{124,105,82,71,48,52,56,75\} .
$$

Data (22) and Fig. 3 show the narrowing of the resultant tube compared to the original one.

If instead of the information set $B$ its approximation by a rectangle (14) is used, then the interval model of the dependence of the microhardness of the zirconium alloy samples on the percentage of oxygen will take the form:

$$
[y(x)]=[836 ; 1137]+[2538 ; 4750] \cdot x .
$$

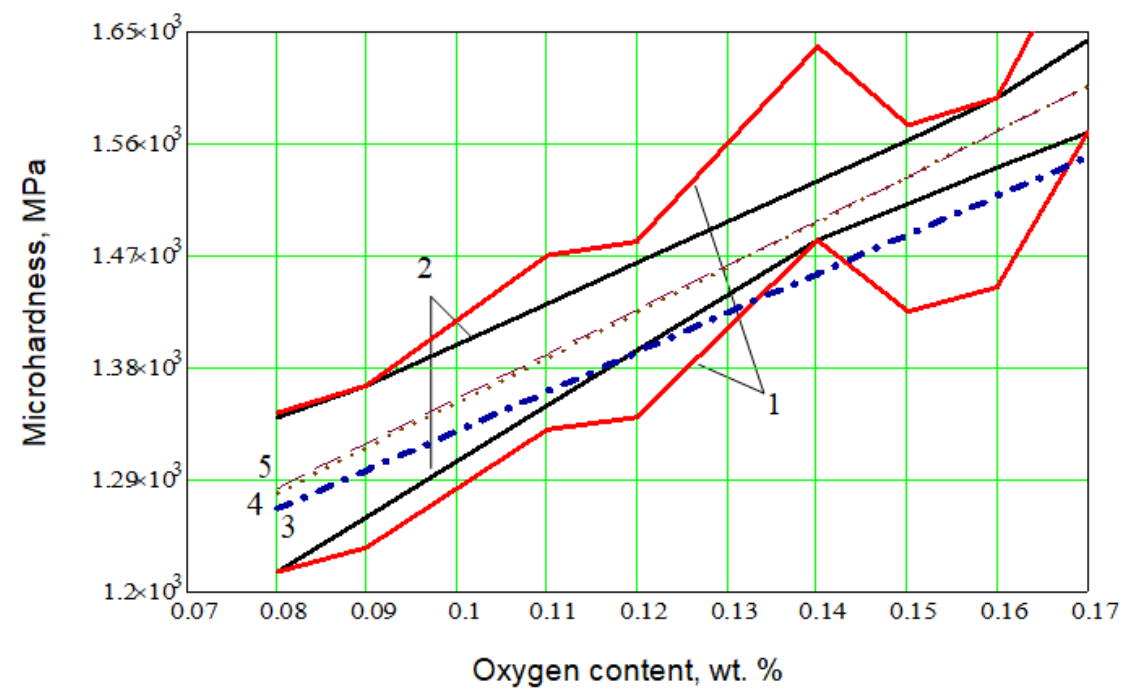

Fig. 3. Interval and point estimates of the forecast model

Using the point estimates of the parameters $\hat{b}_{1}, \hat{b}_{2}$ of the unknown coefficients of the output variable model (microhardness of the zirconium alloy sample) with a fixed vector of the input variable (content of oxygen), it is possible to construct a point estimate defining some prediction model. So for estimating the parameters using the uncertainty center method (15), the direct forecast is the following:

$$
y(x)=986.5+3644 \cdot x
$$

for evaluation using the center of gravity of the set $B$ (16)

$$
y(x)=997+3578 \cdot x
$$

$$
y(x)=1015+3143 \cdot x .
$$

Straight lines (24) and (25) - "dotted" and dashed lines 4, 5 (see Fig. 3) - go through all intervals of uncertainty and practically coincide, and the straight line constructed by the method of least squares, (see Fig. 3, line 3) goes not only outside the tube of the actual values of the output variable, but also outside the intervals of observation uncertainty. This demonstrates the lack of correctness of applying standard procedures for approximating data from a given set of experiments to determine the relationship between the microhardness of the $\mathrm{Zr} 1 \% \mathrm{Nb}$ alloy sample and the percentage of oxygen in it, as well as the correctness of using interval models for this. 


\section{CONCLUSIONS}

Processing the experimental data related to the study of the properties of nuclear materials and, in particular, the $\mathrm{Zr} 1 \% \mathrm{Nb}$ alloy, based on a sample of small length, as well as a possible observation error and the absence of information about its distribution using interval analysis methods, allows for a more correct and complete analysis compared to with commonly used standard statistical processing procedures, for example, linear least squares linear approximation. In this case, the relationship between the microhardness of the $\mathrm{Zr} 1 \% \mathrm{Nb}$ alloy sample and the oxygen content in it, which can be nonlinear with the increase in the sample of observations and taking into account the uncertainties during the experiment, lies within the limits of the socalled interval tube constructed by means of interval analysis methods. This makes it possible to determine more accurately the relationship between these parameters on the basis of a relatively small series of experiments under conditions that occur in the practice of studying the properties of samples of zirconium alloys. It also gives grounds to conclude that it is expedient to apply the methods and models of interval analysis in general for processing the results of similar experiments which aim at studying the properties of nuclear materials.

\section{REFERENCES}

1. M.M. Pylypenko. High pure zirconium // Problems of Atomic Science and Technology. Series "Vacuum, Pure materials, Superconductors". 2018, N 1, p. 3-8.

2. O.V. Yefimov, M.M. Pylypenko, T.V. Potanina, V.L. Kavertsev, T.A. Harkusha. Reactors and steam generators of NPS unit: schemes, processes, materials, designs, models. Kharkiv: "V spravi”, 2017, 420 p.

3. M.M. Pylypenko. Physical and technological basis of the zirconium materials and hafnium creation technology for the cores of nuclear power plants: Doctoral thesis. Kharkiv, 2012, 313 p.

4. S.D. Lavrinenko, M.M. Pylypenko, A.A. Drobyshevska, et al. Zr1Nb alloy based on magnesiumthermal zirconium // Problems of Atomic Science and Technology. Series "Vacuum, Pure materials, Superconductors”. 2016, N 1, p. 10-13.

5. V.M. Glazov, V.N. Vigdorovich. Microhardness of metals. M.: "Metallurgy", 1969, 247 p.

6. A.P. Voshchinin, G.R. Sotirov. Optimization under uncertainty. Publishing house "MEI", 1989, $224 \mathrm{p}$.

7. Romon E. Moore, R. Baker Kearfott, Michael J. Could. Introduction to interval analysis. Philadelphia: Society for Industrial and Applied Mathematics, 2009, $223 \mathrm{p}$.

8. T.V. Potanina, A.V. Yefimov, T.A. Yesypenko, T.A. Harkusha. Application of interval analysis methods for NPP safety analysis // Nuclear and Radio Safety. 2018, N 3, p. 23-29.

9. S.I. Kumkov. Processing experimental data on ionic conductivity of molten electrolyte using interval analysis methods // Melts. 2010, N 3, p. 79-89.

10. S.I. Zhilin. Experiments on the estimation of the parameters of empirical dependence by the method of least squares and the center of uncertainty // News of the Altai State University. 2003, N 1, p. 24-27.

11. Jesse Russell. Generalized Least Squares Method. M.: "VSD”, 2013, 164 p.

Article received 15.05.2019

\title{
ОБРАБОТКА ЭКСПЕРИМЕНТАЛЬНЫХ ДАННЫХ ПРОЦЕССА РАФИНИРОВАНИЯ ЯДЕРНОГО МАТЕРИАЛА Zr1\% Nb ЭЛЕКТРОННО-ЛУЧЕВОЙ ПЛАВКОЙ МЕТОДАМИ ИНТЕРВАЛЬНОГО АНАЛИЗА
}

\author{
А.В. Ефимов, Н.Н. Пилипенко, Т.В. Потанина, Т.А. Есипенко, \\ Т.А. Гаркуша, Ю.С. Стадник
}

Исследованы возможности применения методов и моделей интервального анализа, учитывающих неопределенности в задании данных для сплавов $\mathrm{Zr} 1 \% \mathrm{Nb}$, для более точного определения взаимосвязи между микротвердостью образцов сплава $\mathrm{Zr} 1 \% \mathrm{Nb}$ и процентным содержанием кислорода в них. Показана корректность применения методов и моделей интервального анализа для обработки результатов экспериментов по изучению свойств ядерных материалов.

\section{ОБРОБКА ЕКСПЕРИМЕНТАЛЬНИХ ДАНИХ ПРОЦЕСУ РАФІНУВАННЯ ЯДЕРНОГО МАТЕРІАЛУ Zr1\%Nb ЕЛЕКТРОННО-ПРОМЕНЕВОЮ ПЛАВКОЮ МЕТОДАМИ ІНТЕРВАЛЬНОГО АНАЛІЗУ}

\author{
О.В. Сфімов, М.М. Пилипенко, Т.В. Потаніна, Т.О. Ссипенко, \\ Т.А. Гаркуша, Ю.С. Стаднік
}

Досліджено можливості застосування методів і моделей інтервального аналізу, що враховують невизначеності в заданні даних для сплавів $\mathrm{Zr} 1 \% \mathrm{Nb}$, для більш точного визначення взаємозв'язку між мікротвердістю зразків сплаву Zr1\% $\mathrm{Nb}$ та процентним вмістом кисню в них. Показана коректність застосування методів і моделей інтервального аналізу для обробки результатів експериментів 3 вивчення властивостей ядерних матеріалів. 